\title{
Selective IR-induced isomerization of 1,2-dichloropropane isolated in xenon matrix
}

\author{
Adriana Olbert-Majkut ${ }^{\mathrm{a}, \mathrm{b}}$, Igor D. Reva ${ }^{\mathrm{b}}$, Rui Fausto ${ }^{\mathrm{b}, *}$ \\ ${ }^{a}$ Faculty of Chemistry, Wrocław University, F. Joliot-Curie Street 14, Wrocław, Poland \\ ${ }^{\mathrm{b}}$ Department of Chemistry, University of Coimbra, 3004-535 Coimbra, Portugal
}

\section{A R T I C L E I N F O}

\section{Article history:}

Received 5 February 2008

In final form 12 March 2008

Available online 17 March 2008

\begin{abstract}
A B S T R A C T
The conformations of monomeric 1,2-dichloropropane isolated in low temperature xenon matrix were characterized experimentally using FTIR spectroscopy. The interpretation of the experimental spectra was aided by $a b$ initio MP2/6-311++G(3df,3pd) calculations. Relative energies of three structures, differing by the orientation of the $\mathrm{Cl}-\mathrm{C}-\mathrm{C}-\mathrm{Cl}$ dihedral angle, fall within $0-6 \mathrm{~kJ} \mathrm{~mol}^{-1}$ range. The spectral signatures of all three conformers were identified experimentally. Infrared irradiation of the matrix isolated compound resulted in selective conversion of the most stable Trans conformer into the higher energy Gauche+ rotamer, while the Gauche- conformer remained unaffected. This result was interpreted in terms of calculated energy barriers and dipole moments.
\end{abstract}

(c) 2008 Elsevier B.V. All rights reserved.

\section{Introduction}

Chloroalkanes are organic compounds mostly known as environmental pollutants. They represent a class of potential human mutagenic agents and carcinogens. One representative of this class of compounds is 1,2-dichloropropane (1,2-DCP). It is a colorless, flammable liquid with a chloroform-like odor. The greatest use of 1,2 -DCP is in making other organic chemicals, in particular perchloroethylene and several other related chlorinated chemicals. In the past, 1,2-DCP was released into soil during its former use as a fumigant to control root parasitic nematodes for a variety of crops, and into air and in wastewater as fugitive emissions during its production or use in chemical industry and applications as solvent, scouring, spotting and metal degreasing agent [1]. If released in air, 1,2-DCP will degrade by reaction with photochemically produced hydroxyl radicals (half-life $>23$ days). Therefore, there will be ample time for dispersal as is evidenced by its still usual presence in ambient air in regions where it is produced or used $[1,2]$. Elimination from atmosphere by rain is, however, relatively efficient due to its moderate water solubility $(2.7 \mathrm{~g} / \mathrm{L})$. On the other hand, this property facilitates appearance of 1,2-DCP as an important pollutant of groundwater systems, where its estimated half-life ranges from 6 months to 2 years $[1,3]$.

In spite of its still very significant uses and hazardous chemical properties, 1,2-DCP has not attracted much attention regarding its molecular properties, which are ultimately responsible for the chemical and biochemical activities of the compound. Previous studies on this compound in gaseous, liquid, amorphous solid phases and in solutions revealed that in disordered phases

\footnotetext{
* Corresponding author. Fax: +351 239827703

E-mail address: rfausto@ci.uc.pt (R. Fausto).
}

1,2-DCP exists as a mixture of trans and gauche conformers, with the form bearing two chlorine atoms in the trans position being the most populated [4-12].

In more polar media, comparatively larger concentrations of the two more polar gauche conformers were observed [9]. On the other hand, at least two crystalline modifications of 1,2-DCP have been observed spectroscopically [9]. According to Guirgis et al. [9], they should contain different percentages of the 1,2-DCP conformers, with each crystal containing predominantly a given conformer. The particular type of crystal structure depends on crystallization conditions: in the liquid phase or in polar solvents associates of the minor (but more polar) gauche conformers might be more stable than those built from the trans conformer, and then act as occasional nucleating seeds for growth of crystals consisting predominantly of one of the gauche conformers [9]. The two crystalline modifications investigated by Guirgis et al. could not however be characterized structurally, and a detailed study of the solid phases of neat $1,2-\mathrm{DCP}$ is still missing.

The previous studies on 1,2-DCP [4-12] showed the importance of the local environment in determining the relative amounts of different conformers of the compound. Since the compound has never been studied before under cryogenic matrix conditions, in the present study the matrix isolation technique coupled with infrared spectroscopy (and supported by high-level theoretical calculations) was used to investigate the conformational preferences of monomeric 1,2-DCP. In particular, two main questions were addressed: (1) how the gas phase conformational equilibrium of 1,2-DCP is affected by deposition of the compound in a low temperature rare gas matrix? (i.e., can the gas phase equilibrium populations of the 1,2-DCP conformers be efficiently trapped in a cryogenic matrix?), (2) is it possible to induce conformational isomerization reactions for the matrix isolated compound, either 
thermally (by annealing of the matrix) or photochemically (by in situ irradiation of the matrix)?

It is worth noting that the low temperature matrix isolation method is a powerful technique that can provide well-resolved vibrational spectra of organic molecules and then has been used successfully for many years to identify and characterize rotational isomers, even when they possess closely matching spectra [13-16]. Moreover, besides the high intrinsic resolution of matrix isolation spectra, the conformational composition of a given compound in a matrix can very often be changed either thermally or photochemically [17], thus allowing a more reliable experimental identification of different rotamers and their spectroscopic characterization. For 1,2-DCP, the trans conformer has already been characterized spectroscopically in the past in some detail [4-12]. However, there is lack of reliable data for the two gauche conformers.

\section{Materials and methods}

\subsection{Experimental details}

1,2-Dichloropropane was obtained from Aldrich (purity 99.5\%). A glass vacuum system and standard manometric procedures were used to deposit the matrix gas (xenon, 99.995\% obtained from Air Liquide). Matrices were prepared by co-deposition of xenon and 1,2-DCP, onto a cooled CSI window, which was held during the experiment at $20 \mathrm{~K}$ by means of a closed cycle helium refrigeration system (APD Cryogenics, Displex 202 A). During the matrix deposition, a glass container with 1,2-DCP was thermostatted in ice/ water mixture at $273 \mathrm{~K}$, which allowed to reduce the saturated vapor pressure above the compound and to control better the deposition process. The glass tube was attached to the vacuum chamber of the cryostat via a needle valve kept at room temperature $(298 \mathrm{~K})$. This temperature then defined the conformational composition of the compound in the gaseous phase immediately before deposition of the matrix.

The infrared spectra, in the range $4000-400 \mathrm{~cm}^{-1}$, were recorded with $0.5 \mathrm{~cm}^{-1}$ spectral resolution using a Mattson (Infinity 60AR Series) Fourier Transform infrared spectrometer equipped with a DTGS detector and $\mathrm{Ge} / \mathrm{KBr}$ beamsplitter.

The samples were irradiated (through the outer $\mathrm{KBr}$ window of the cryostat) with infrared light emitted by a kanthal wire electrically heated to an orange glow. Spectra were recorded after 210 and $400 \mathrm{~min}$ of IR irradiation.

\subsection{Computational details}

All calculations were carried out at the MP2/6-311++G(3df,3pd) level of theory using the GaUsSian 03 program [18]. At the optimized geometries, the harmonic vibrational frequencies and infrared intensities were calculated for all stationary points investigated (the three different minimum energy conformations of the compound and three first order transition states interconnecting them). The obtained frequencies were used to assist the analysis of the experimental spectra, and to account for the zero-point vibrational energy (ZPVE) corrections and also to confirm the nature of the obtained stationary points. The identity of the calculated transition states was further verified by intrinsic reaction coordinate (IRC) calculations [19,20]. The calculated frequencies were scaled by 0.940 above $2800 \mathrm{~cm}^{-1}$ (C-H stretching vibrations), by 0.933 between 800 and $600 \mathrm{~cm}^{-1}$ (C-Cl stretching vibrations) and by 0.966 between 1600 and $800 \mathrm{~cm}^{-1}$ as well as below $600 \mathrm{~cm}^{-1}$ (fingerprint region). The scaling factors were determined by linear fitting with intercept zero, correlation coefficients being between 1 and 0.9996 . For the fingerprint region 14 experimental and calculated frequencies of the trans isomer were used.

\section{Results and discussion}

\subsection{Geometries, energies and isotopes}

The highest possible symmetry of the 1,2-DCP molecule is $C_{1}$, which means that all possible minima are formally different. There is one chiral centre in the molecule, which can result in two enantiomers ( $R$ and $S$ ). At the monomer level, they are spectroscopically, conformationally and energetically equivalent. Only one form, with S configuration around the chiral centre, was considered in this study, for simplicity. Different previous studies described different chiral isomers of 1,2-DCP. The early work of Nomura et al. [12] considered the $S$ configuration of 1,2-DCP, similarly to the present study. The works of Tague et al. [11] and of Guirgis et al. [9] reported geometries corresponding to $\mathrm{R}$ enantiomer, and their notation for the gauche conformers is opposite comparing to the present study. Whenever comparing our results with these previous studies we took this into consideration.

The 1,2-DCP molecule has only one conformationally relevant degree of freedom, which is related to the $\mathrm{Cl}-\mathrm{C}-\mathrm{C}-\mathrm{Cl}$ dihedral angle (see Fig. 1). Considering three conformational possibilities (Trans, $180^{\circ}$; + Gauche, $60^{\circ}$; and - Gauche, $-60^{\circ}$ ), unique names can be given to the three possible conformers: Trans, Gauche+ and Gauche-, respectively, from here abbreviated as T, G+ and $\mathrm{G}-$. Indeed, these three minima have been found on the potential energy surface of 1,2-DCP (Fig. 2).

According to the MP2/6-311++G(3df,3pd) calculations, the global minimum corresponds to the T conformer, with the $\mathrm{Cl}-\mathrm{C}-\mathrm{C}-\mathrm{Cl}$ torsional angle $(\Theta)$ equal to $173.6^{\circ}$ (see Fig. 2 and also Table $\mathrm{S} 1$, provided as Supplementary material), while for the less stable G+ and $\mathrm{G}-$ conformers $\Theta=66.0^{\circ}$ and $-67.2^{\circ}$, respectively. The $\mathrm{G}-$ and $\mathrm{G}+$ conformers lay 5.5 and $5.8 \mathrm{~kJ} \mathrm{~mol}^{-1}$ (ZPVE included), respectively, above the global minimum.

Analysis of the relative energies and geometries shows that the most stable structure is realized when the distance between the

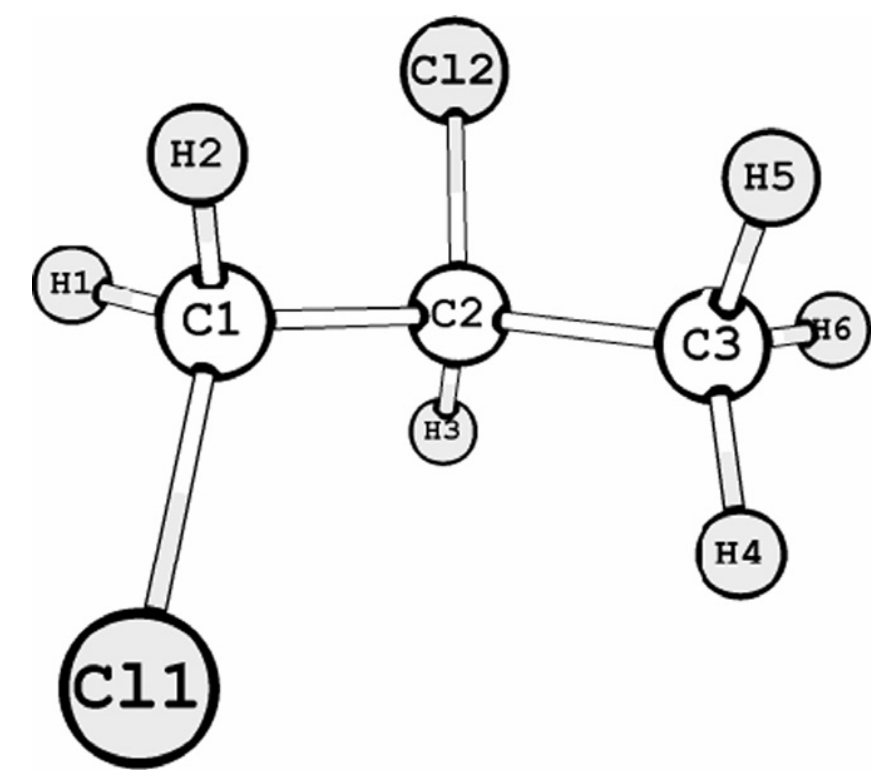

Fig. 1. Molecule of 1,2-dichloropropane and adopted atom numbering. 


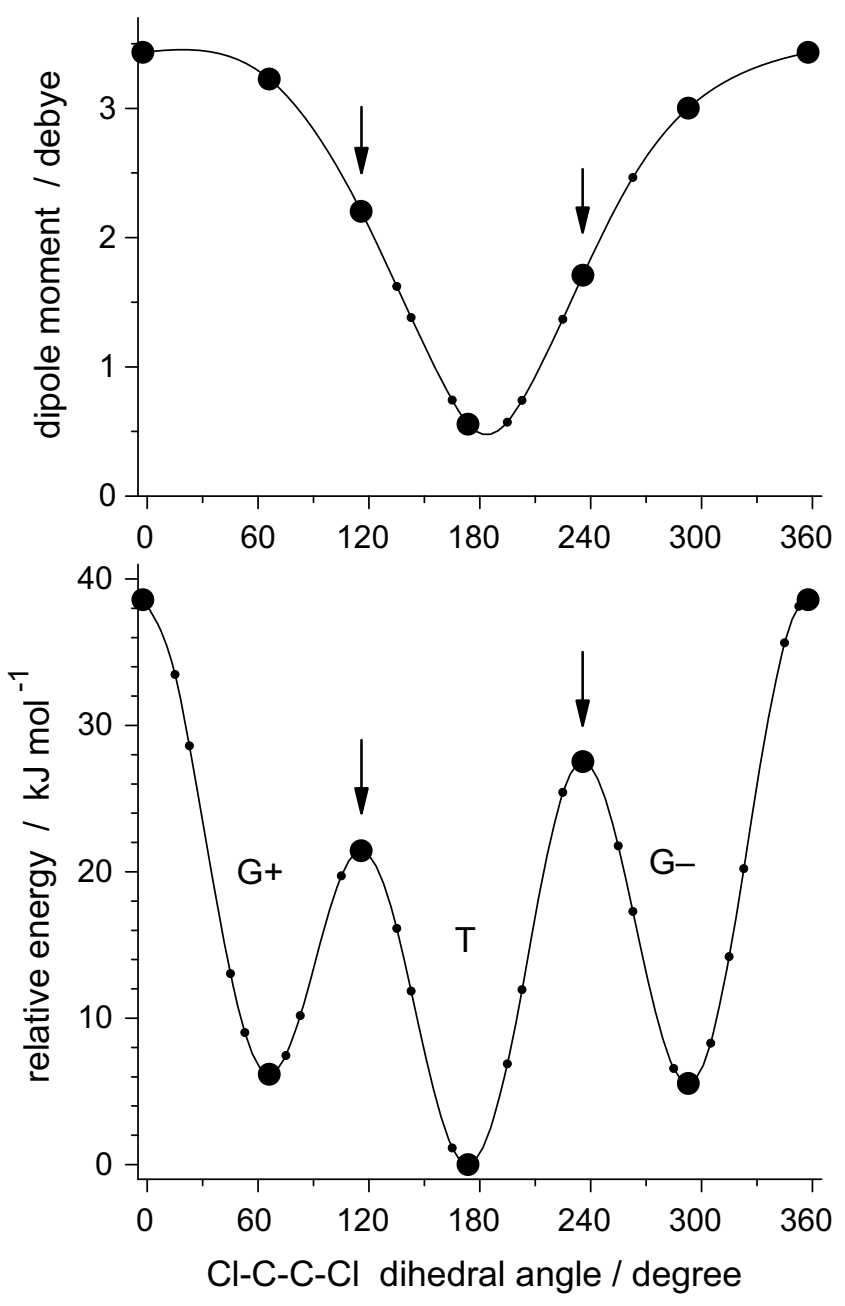

Fig. 2. Internal rotation around the $\mathrm{Cl}-\mathrm{C}-\mathrm{C}-\mathrm{Cl}$ dihedral angle $(\Theta)$ in molecule of 1,2-DCP. Lower frame: Relaxed potential energy scan calculated at the MP2/6-311++G(3df,3pd) level. Upper frame: Total molecular dipole moment of $1,2-\mathrm{DCP}$ as a function of $\Theta$. Arrows in both frames indicate two transition states (TG+ and $\mathrm{TG}-$ ). Large dots correspond to the stationary points.

two chlorine atoms is maximal, i.e. when the $\mathrm{Cl}-\mathrm{C}-\mathrm{C}-\mathrm{Cl}$ dihedral angle adopts the trans orientation. Such a configuration allows minimizing the repulsive interaction between chlorines - two bulky negative units in 1,2-DCP. On the other hand, the stability of the two gauche forms is predicted to be very close. Indeed, upon accounting for the zero-point vibrational contribution, the energies of $\mathrm{G}+$ and $\mathrm{G}$ - are within $0.3 \mathrm{~kJ} \mathrm{~mol}^{-1}$, whereas for the Gibbs free energies, this difference is reduced even more, down to $0.05 \mathrm{~kJ} \mathrm{~mol}^{-1}$ (see Table S2 in the Supplementary material).

Chlorine element naturally occurs in two isotopes, ${ }^{35} \mathrm{Cl}$ and ${ }^{37} \mathrm{Cl}$, in the ratio of $75.78: 24.22 \%$, respectively. Combinations of ${ }^{35} \mathrm{Cl}$ and ${ }^{37} \mathrm{Cl}$ result in four isotopic variations of $1,2-\mathrm{DCP}$ molecule. In the following text, the compound in its ${ }^{X} \mathrm{ClC}_{(1)} \mathrm{H}_{2}-{ }^{Y} \mathrm{ClC}_{(2)} \mathrm{H}-\mathrm{C}_{(3)} \mathrm{H}_{3}$ isotopic variety will be abbreviated as $(X)(Y)$, where $X$ and $Y$ are masses of chlorine isotopes at $C_{(1)}$ and $C_{(2)}$ positions. The natural abundances of chlorine isotopes (let us call them ${ }^{(35)} A$ and ${ }^{\left({ }^{37)}\right.} A$ ) can be seen as the probability of the chlorine element to exist as a given isotope. Assuming that bonding with ${ }^{35} \mathrm{Cl}$ or ${ }^{37} \mathrm{Cl}$ isotopes occurs with the same probability, one calculates the probability ${ }^{(X)(Y)} \mathrm{P}$ of the $(X)(Y)$ isotopic combination in $1,2-\mathrm{DCP}$ as the product of probabilities of occurrence of the particular isotopes, from the following formula:
${ }^{(X)(Y)} P={ }^{(X)} A \times{ }^{(Y)} A$,

where both $X$ and $Y$ assume values 35 and $37,{ }^{(35)} A$ and ${ }^{(37)} A$ are the natural abundances of ${ }^{35} \mathrm{Cl}$ and ${ }^{37} \mathrm{Cl}$, respectively. Accordingly, the (35)(35), (35)(37), (37)(35) and (37)(37) isotopic variations of 1,2 -DCP have statistical weights of $57.426 \%, 18.354 \%, 18.354 \%$ and $5.866 \%$, respectively. Formally, these four isotopic combinations represent four different compounds, with different vibrational spectra and different thermochemistry.

In line with the calculated relative Gibbs free energies $(0,5.73$ and $5.78 \mathrm{~kJ} \mathrm{~mol}^{-1}$ for $\mathrm{T}, \mathrm{G}-$ and $\mathrm{G}+$, respectively), the equilibrium conformational mixture of 1,2-DCP at room temperature (298 K), as obtained from the Boltzmann distribution, is expected to consist of $83.6 \% \mathrm{~T}, 8.27 \% \mathrm{G}-$ and $8.13 \% \mathrm{G}+$ conformers, for the most abundant (35)(35) isotopic variation. The relative Gibbs free energies at $298 \mathrm{~K}$ for conformers of all four isotopomers of 1,2-DCP match each other. Then, the equilibrium conformational populations ( $T, G-$ and $\mathrm{G}^{+}$) coincide for $(35)(35)$ and remaining three isotopomers (see Table S2).

In order to evaluate the possibility of conformational interconversions in matrices, the relaxed potential energy scan for rotation around the $\mathrm{Cl}-\mathrm{C}-\mathrm{C}-\mathrm{Cl}$ torsional angle was carried out and energy barriers separating different conformers were calculated (see Fig. 2). The barriers separating the most stable $\mathrm{T}$ isomer from the less stable $\mathrm{G}-$ and $\mathrm{G}+$ conformers amount to 27.6 and $21.1 \mathrm{~kJ} \mathrm{~mol}^{-1}$ (including ZPVE), respectively. The transition states associated with the $\mathrm{T} \leftrightarrow \mathrm{G}-$ and $\mathrm{T} \leftrightarrow \mathrm{G}+$ isomerization processes $\left(\mathrm{TS}_{\mathrm{TG}-}\right.$ and $\mathrm{TS}_{\mathrm{TG}^{+}}$) are characterized by $\Theta$ dihedral angles of $-124.2^{\circ}$ and $115.8^{\circ}$, respectively. These transition states have associated imaginary frequencies of $120 \mathrm{i}$ and $102 \mathrm{i} \mathrm{cm}{ }^{-1}$, respectively, corresponding to the internal rotation around the $\mathrm{C}_{(1)}-\mathrm{C}_{(2)}$ bond. The calculated barriers for conversion of $\mathrm{G}-$ and $\mathrm{G}+$ conformers into the most stable $\mathrm{T}$ form are 22.1 and $15.3 \mathrm{~kJ} \mathrm{~mol}^{-1}$. The direct isomerization between $\mathrm{G}^{+}$and $\mathrm{G}-$ conformers faces the highest energy transition state $\left(\mathrm{TS}_{\mathrm{G}+\mathrm{G}_{-}}\right)$lying $38.3 \mathrm{~kJ} \mathrm{~mol}^{-1}$ above the global minimum. This transition state is characterized by $\Theta=-2.3^{\circ}$ and the imaginary frequency of $141 \mathrm{i} \mathrm{cm}^{-1}$. The calculated energy barrier for the direct $\mathrm{G}+\rightarrow \mathrm{G}-$ conversion is above $32 \mathrm{~kJ} \mathrm{~mol}^{-1}$ and is then $5-10 \mathrm{~kJ} \mathrm{~mol}^{-1}$ higher than those obtained for the $\mathrm{T} \leftrightarrow \mathrm{G}^{+}$and $\mathrm{T} \leftrightarrow \mathrm{G}-$ processes.

The methyl torsional barrier in 1,2-DCP was also calculated in this work. For all conformers it was found to fall within a narrow range $14.5-14.9 \mathrm{~kJ} \mathrm{~mol}^{-1}$ (at the MP2/6-311++G(3df,3pd) level, including ZPVE). Previous microwave studies on ethane [21] and chloro-substituted ethanes $\left(\mathrm{CH}_{2} \mathrm{Cl}-\mathrm{CH}_{3}\right.$ [22] and $\mathrm{CHCl}_{2}-\mathrm{CH}_{3}$ [23]) indicate that, in this series, the internal barrier for methyl rotation increases with the number of chlorine atoms, amounting respectively to $12.0,14.8$ and $17.8 \mathrm{~kJ} \mathrm{~mol}^{-1}$. Further, the $\mathrm{HF} /$ $6-31 \mathrm{G}^{*}$ calculated energy barrier for rotation of methyl group in propane was $14.0 \mathrm{~kJ} \mathrm{~mol}^{-1}$ [24]. Hence, the predicted barrier for the methyl internal rotation in 1,2-DCP is within the expected energy range.

\subsection{Matrix isolation experiments}

Fig. 3 represents the experimental FTIR spectrum of 1,2-DCP isolated in a xenon matrix, immediately after deposition at $20 \mathrm{~K}$ (top frame). The experimental spectrum is compared with the population-weighted simulated spectrum (middle frame) for twelve individual species (considering all three conformers in all four isotopic variations of the compound). This Figure also shows the $a b$ initio spectra for the three conformers T, G+ and G- of the most abundant (35)(35) isotopologue (bottom frame). For the remaining isotopic modifications, the relative intensities of the bands due to the different conformers are very similar to those 

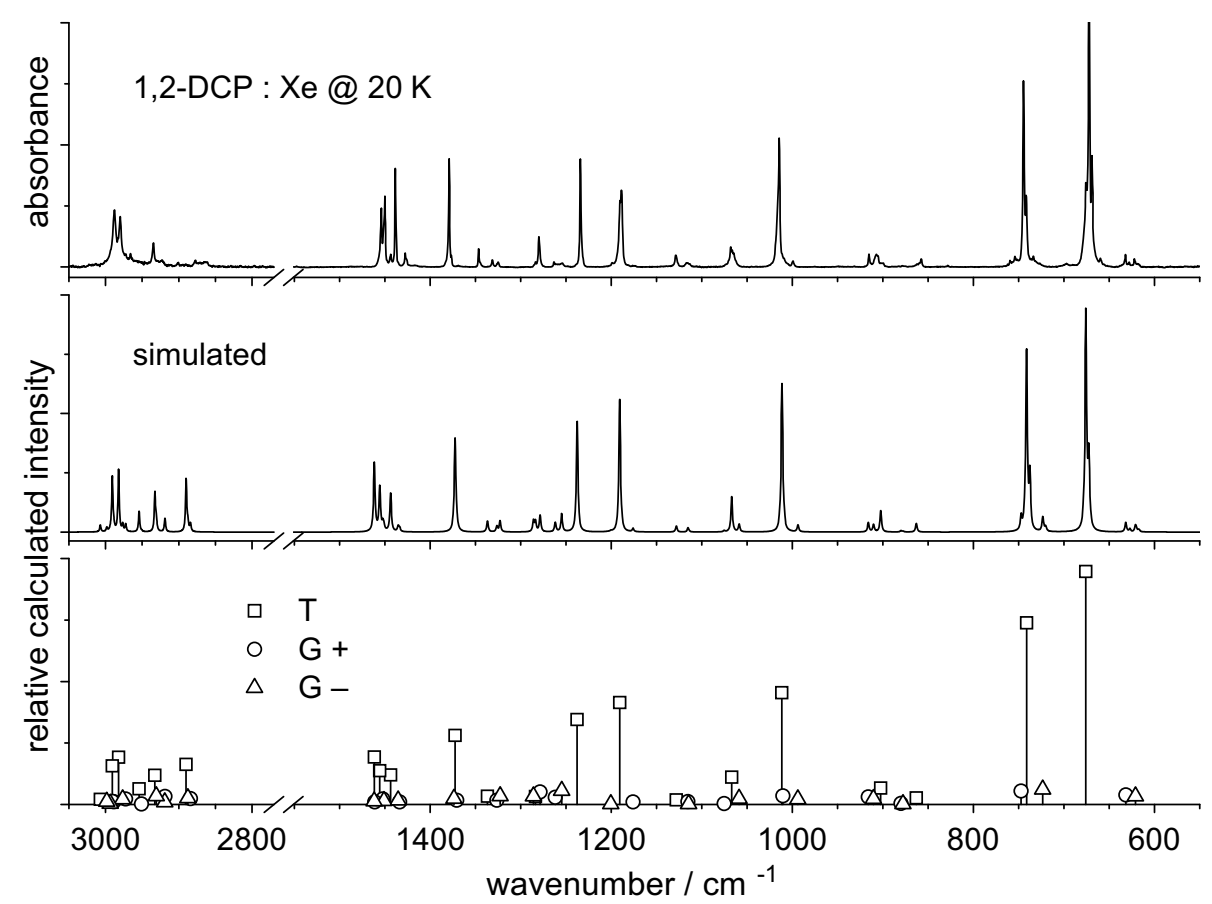

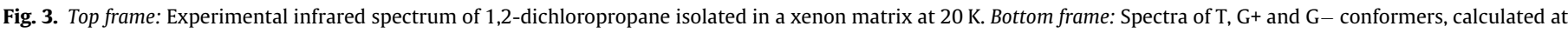

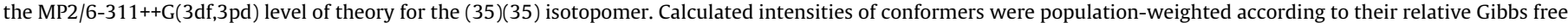

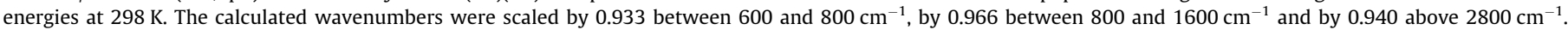

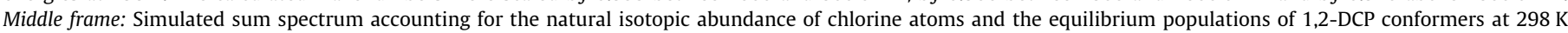

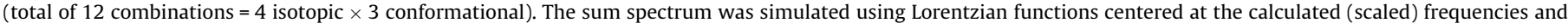
with bandwidth-at-half-height equal to $2 \mathrm{~cm}^{-1}$.

found for the (35)(35) isotopologue and were not included in Fig. 3 for simplicity.

The careful analysis of the experimental results clearly reveals the presence in the matrix of small amounts of both $\mathrm{G}^{+}$and $\mathrm{G}$ - conformers along with the dominant spectral signature of $\mathrm{T}$ form. Moreover, the good match obtained between the experimental and simulated spectra shows that the conformational equilibrium existing in the gaseous phase prior to deposition could be efficiently trapped in the matrix. This result is in agreement with the relatively high isomerization barriers $\left(>15 \mathrm{~kJ} \mathrm{~mol}^{-1}\right)$ obtained theoretically (see Fig. 2).

Table 1 contains the observed and calculated frequencies and results of normal coordinate analysis for 1,2-DCP (see Table S3 for definition of internal coordinates used in the vibrational calculations). The general assignment of the experimental spectrum was carried out on the basis of comparison with the results obtained theoretically. Moreover, the assignment of bands to different conformers was also facilitated by the comparison of the spectra registered before and after IR irradiation of the matrix (which, as described below, led to conversion of $\mathrm{T}$ into $\mathrm{G}+$ form, while G- conformer stayed unaffected).

The extended basis set [6-311++G(3df,3pd)] used in the present theoretical calculations considerably improved the obtained frequency values as compared with the results of MP2/6-31G ${ }^{*}$ calculations reported previously [9]. The comparison of our experimental results with the previous data [9] leads also to the conclusion that for the majority of the bands observed in the spectrum of the matrix isolated 1,2-DCP, which could be assigned to conformer $\mathrm{T}$, the assignments closely follow those previously proposed for the amorphous solid and gaseous phase. The main discrepancy concerns the assignment of the $\mathrm{CCl}$ stretching vibrations. In ref. [9], the $v \mathrm{CCl}_{(1)}$ mode in $\mathrm{T}$ and $\mathrm{G}+$ conformers in the amorphous solid state were assigned to features at 740 and $723 \mathrm{~cm}^{-1}$, respec- tively (the band due to the G- was not observed). ${ }^{1}$ The present study doubtlessly showed that in the spectrum of matrix isolated 1,2-DCP, the $v \mathrm{CCl}_{(1)}$ bands due to the $\mathrm{T}$ and $\mathrm{G}+$ conformers appear as a doublet at $744.6 / 741.7 \mathrm{~cm}^{-1}$ and as a multiplet at $759.6 /$ $754.0 / 751.8 \mathrm{~cm}^{-1}$, respectively. In turn, the bands at 733.8 and $731.5 \mathrm{~cm}^{-1}$ shall be assigned to the $v \mathrm{CCl}_{(1)}$ mode in $\mathrm{G}-$. On the other hand, the bands due to the ${ } \mathrm{CCl}_{(2)}$ vibration in the matrix isolated 1,2-DCP were observed at $676.0 / 672.2 / 669.0 \mathrm{~cm}^{-1}$, for $\mathrm{T}$; $622.3 /$ $618.4 \mathrm{~cm}^{-1}$ for $\mathrm{G}-$; and $632.0 / 627.8 \mathrm{~cm}^{-1}$, for $\mathrm{G}+$, while according to the results of Guirgis et al. [9] the $v \mathrm{CCl}_{(2)}$ bands in the spectra of the amorphous solid state appear at 667 and $617 \mathrm{~cm}^{-1}$, for the T and $\mathrm{G}-$ conformers, respectively (no band due to $\mathrm{G}+$ conformer has been detected in infrared).

At this point it should be emphasized that the observed splitting in the region of $v \mathrm{CCl}$ vibrations is due to the isotopic effect. Fig. 4 shows the $v \mathrm{CCl}$ region of the spectra of 1,2-DCP monomers, with the theoretically predicted spectra in the bottom frame. According to the calculations, isotopic splitting for all conformers (T, G+, G-), including both $v \mathrm{CCl}_{(1)}$ and $\nu \mathrm{CCl}_{(2)}$ modes, amounts to $4 \pm 0.5 \mathrm{~cm}^{-1}$. Indeed, as mentioned above, all $v \mathrm{CCl}$ modes exhibit splitting of this magnitude in the experimental spectra.

Further validity of spectral assignments was provided by results of broadband infrared irradiation. After 210 min of irradiation, the spectrum of the sample changed, while subsequent irradiation (up to $400 \mathrm{~min}$ ) did not induce further spectral changes, suggesting that a photostationary state was achieved. The amount of reacted compound was small and equal to ca. $5 \%$ of conformer $\mathrm{T}$, whose bands decreased upon irradiation. Assignment of the consumed species to conformer $\mathrm{T}$ was straightforward since absorptions of this conformer strongly dominated the spectrum of the matrix

\footnotetext{
[9].
} 
Table 1

Experimental (xenon matrix, $20 \mathrm{~K}$ ) and calculated [MP2/6-311++G(3df,3pd)] wavenumbers and infrared intensities for T, G+ and G- conformers of 1,2-DCPa

\begin{tabular}{|c|c|c|c|c|c|c|c|c|c|c|c|}
\hline \multicolumn{4}{|l|}{ Conformer T } & \multicolumn{4}{|c|}{ Conformer G+ } & \multicolumn{4}{|c|}{ Conformer G- } \\
\hline \multirow[t]{2}{*}{ Exp. } & \multicolumn{3}{|l|}{ Calc. } & \multirow[t]{2}{*}{ Exp. } & \multicolumn{3}{|l|}{ Calc. } & \multirow[t]{2}{*}{ Exp. } & \multicolumn{3}{|l|}{ Calc. } \\
\hline & $v$ & I & PED & & $v$ & $I$ & PED & & $v$ & I & PED \\
\hline 3000.6 & 3007 & 0.9 & $94 v \mathrm{CH}_{2}$ as & 2993.0 & 2991 & 5.3 & $45 v \mathrm{CH}_{3}$ as $+43 v \mathrm{CH}_{2}$ as & 2996.5 & 2998 & 5.0 & $65 v \mathrm{CH}_{3}$ as $+32 v \mathrm{CH}_{3}$ as \\
\hline 2987.9 & 2991 & 6.4 & $101 \mathrm{vCH}_{3}$ as & - & 2989 & 4.7 & $54 v \mathrm{CH}_{3}$ as $+48 v \mathrm{CH}_{2}$ as & - & 2993 & 1.5 & $96 v \mathrm{CH}_{2}$ as \\
\hline $\begin{array}{l}2983.1 \\
2980.0\end{array}$ & 2982 & 7.8 & $93 v^{2} \mathrm{CH}_{3}$ as & 2973.3 & 2972 & 9.5 & $84 v \mathrm{CH}_{3}$ as $^{\prime}$ & 2975.7 & 2977 & 9.1 & $64 v \mathrm{CH}_{3}$ as $+40 v \mathrm{CH}_{3}$ as \\
\hline 2965.8 & 2954 & 2.6 & $88 v \mathrm{C}-\mathrm{H}$ & 2949.1 & 2951 & 1.0 & $88 v \mathrm{C}-\mathrm{H}$ & 2927.8 & 2931 & 14.1 & $78 v \mathrm{C}-\mathrm{H}+20 v \mathrm{CH}_{2} \mathrm{~s}$ \\
\hline 2934.6 & 2933 & 4.8 & $94 v \mathrm{CH}_{2} \mathrm{~S}$ & 2922.9 & 2919 & 14.0 & $98 v \mathrm{CH}_{2} \mathrm{~S}$ & - & 2919 & 4.1 & $76 v \mathrm{CH}_{2} \mathrm{~s}+21 v \mathrm{C}-\mathrm{H}$ \\
\hline 2877.6 & 2890 & 6.6 & $105 v^{2} \mathrm{CH}_{3} \mathrm{~s}$ & 2864.0 & 2884 & 10.0 & $106 v \mathrm{CH}_{3} \mathrm{~s}$ & 2870.0 & 2888 & 10.7 & $103 v \mathrm{CH}_{3} \mathrm{~s}$ \\
\hline 1453.9 & 1462 & 7.8 & $66 \delta \mathrm{CH}_{3} \mathrm{as}^{\prime}+21 \delta \mathrm{CH}_{2}$ & 1455.7 & 1461 & 4.4 & $85 \delta \mathrm{CH}_{3}$ as & - & 1462 & 5.6 & $65 \delta \mathrm{CH}_{3}$ as $+23 \delta \mathrm{CH}_{3}$ as \\
\hline $\begin{array}{l}1451.0 \\
1449.9\end{array}$ & 1456 & 5.6 & $76 \delta \mathrm{CH}_{3}$ as & 1443.5 & 1452 & 9.3 & $80 \delta \mathrm{CH}_{3}$ as & - & 1451 & 6.3 & $63 \delta \mathrm{CH}_{3}$ as $+17 \delta \mathrm{CH}_{3}$ as \\
\hline $\begin{array}{l}1438.5 \\
1437.7\end{array}$ & 1444 & 4.9 & $74 \delta \mathrm{CH}_{2}+15 \delta \mathrm{CH}_{3} \mathrm{as}^{\prime}$ & $\begin{array}{l}1427.5 \\
1425.8\end{array}$ & 1434 & 4.4 & $94 \delta \mathrm{CH}_{2}$ & 1435.5 & 1435 & 7.1 & $85 \delta \mathrm{CH}_{2}$ \\
\hline $\begin{array}{l}1382.5 \\
1378.9\end{array}$ & 1372 & 11.4 & $96 \delta \mathrm{CH}_{3} \mathrm{~s}$ & 1376.4 & 1371 & 7.1 & $99 \delta \mathrm{CH}_{3} \mathrm{~s}$ & 1368.9 & 1374 & 9.8 & $90 \delta \mathrm{CH}_{3} \mathrm{~s}$ \\
\hline $\begin{array}{l}1346.2 \\
1344.0\end{array}$ & 1337 & 1.4 & $70 \delta \mathrm{C}-\mathrm{H}$ & 1331.3 & 1326 & 7.3 & $52 \delta \mathrm{C}-\mathrm{H}+31 \mathrm{wCH}_{2}$ & $\begin{array}{l}1326.3 \\
1325.0\end{array}$ & 1323 & 14.1 & $56 \delta \mathrm{C}-\mathrm{H}+27 \mathrm{wCH}_{2}$ \\
\hline 1283.5 & 1284 & 1.3 & $72 \mathrm{wCH}_{2}+26 \gamma \mathrm{C}-\mathrm{H}$ & 1279.6 & 1279 & 21.3 & $75 \gamma \mathrm{C}-\mathrm{H}+17 \mathrm{twCH}_{2}$ & 1285.2 & 1286 & 14.0 & $53 \mathrm{wCH}_{2}+24 \gamma \mathrm{C}-\mathrm{H}+11 v \mathrm{CC}$ as \\
\hline 1234.0 & 1238 & 14.1 & $59 \gamma \mathrm{C}-\mathrm{H}+19 \mathrm{twCH}_{2}+16 \mathrm{wCH}_{2}$ & 1263.4 & 1262 & 12.2 & $61 \mathrm{wCH}_{2}+25 \delta \mathrm{C}-\mathrm{H}$ & $\begin{array}{l}1258.4 \\
1254.1\end{array}$ & 1255 & 23.1 & $51 \gamma \mathrm{C}-\mathrm{H}+14 \mathrm{twCH}_{2}$ \\
\hline $\begin{array}{l}1190.3 \\
1188.3\end{array}$ & 1191 & 16.8 & $46 \mathrm{twCH}_{2}+14 \gamma \mathrm{C}-\mathrm{H}+12 \gamma \mathrm{CH}_{3}$ & $\begin{array}{l}1176.4 \\
1174.1\end{array}$ & 1176 & 4.4 & $58 \mathrm{twCH}_{2}+16 \gamma \mathrm{C}-\mathrm{H}$ & 1199.0 & 1200 & 0.9 & $60 \mathrm{twCH}_{2}+22 \gamma \mathrm{C}-\mathrm{H}$ \\
\hline 1128.7 & 1128 & 0.8 & $70 v \mathrm{CC}$ as & $\begin{array}{l}1116.7 \\
1115.7\end{array}$ & 1115 & 4.9 & $30 v \mathrm{CC}$ as $+19 \gamma \mathrm{CH}_{3}+13 \delta \mathrm{C}-\mathrm{H}+12 \mathrm{twCH}_{2}$ & 1113.3 & 1114 & 1.0 & $48 v \mathrm{CC}$ as $+17 \gamma \mathrm{CH}_{3}^{\prime}$ \\
\hline $\begin{array}{l}1067.8 \\
1066.4 \\
1064.7\end{array}$ & 1067 & 4.5 & $\begin{array}{l}31 \mathrm{twCH}_{2}+18 \gamma \mathrm{CH}_{3}+18 \gamma \mathrm{CH}_{2}+13 \\
v \mathrm{CC} \mathrm{s}\end{array}$ & 1075.3 & 1075 & 1.7 & $27 v \mathrm{CC} \mathrm{s}+23 \gamma \mathrm{CH}_{3}^{\prime}+22 v \mathrm{CC}$ as & - & 1059 & 9.8 & $40 \gamma \mathrm{CH}_{3}+13 \gamma \mathrm{CH}_{2}+10 \mathrm{twCH}_{2}$ \\
\hline $\begin{array}{l}1016.0 \\
1014.5\end{array}$ & 1012 & 18.4 & $\begin{array}{l}44 \gamma \mathrm{CH}_{3}^{\prime}+10 v \mathrm{CC} \text { as }+16 \gamma \mathrm{C}-\mathrm{Cl}_{(2)}+12 \\
\gamma \mathrm{CH}_{3}\end{array}$ & $\begin{array}{l}1011.2 \\
1009.4 \\
1005.5\end{array}$ & 1010 & 14.8 & $26 \gamma \mathrm{CH}_{3}^{\prime}+18 \delta \mathrm{CCCl}_{(1)}+15 \gamma \mathrm{C}-\mathrm{Cl}_{(2)}+15 v \mathrm{CC}$ as & 999.3 & 994 & 8.9 & $44 \gamma \mathrm{CH}_{3}^{\prime}+15 \gamma \mathrm{C}-\mathrm{Cl}_{(2)}+10 v \mathrm{CC}$ as \\
\hline $\begin{array}{l}907.1 \\
905.7\end{array}$ & 902 & 2.7 & $44 v \mathrm{CC} \mathrm{s}+29 \gamma \mathrm{CH}_{3}$ & 915.2 & 916 & 12.8 & $36 v \mathrm{CC} \mathrm{s}+34 \gamma \mathrm{CH}_{3}$ & 913.4 & 910 & 9.6 & $44 \gamma \mathrm{CH}_{3}^{\prime}+15 \gamma \mathrm{C}-\mathrm{Cl}_{(2)}+10 v \mathrm{CC}$ as \\
\hline $\begin{array}{l}862.2 \\
859.7 \\
857.4\end{array}$ & 863 & 1.1 & $65 \mathrm{\gamma CH}_{2}+25 v \mathrm{CC} \mathrm{s}$ & 883.0 & 880 & 1.8 & $57 \gamma \mathrm{CH}_{2}+19 \gamma \mathrm{CH}_{3}^{\prime}$ & 878.3 & 878 & 1.1 & $56 \gamma \mathrm{CH}_{2}+24 v \mathrm{CC} \mathrm{s}$ \\
\hline $\begin{array}{l}744.6\left({ }^{35} \mathrm{Cl}\right) \\
741.7\left({ }^{37} \mathrm{Cl}\right)\end{array}$ & 741 & 30.0 & $73 v \mathrm{CCl}_{(1)}$ & $\begin{array}{l}759.6 \\
754.0\left({ }^{35} \mathrm{Cl}\right) \\
751.8\left({ }^{(37} \mathrm{Cl}\right)\end{array}$ & 747 & 23.0 & $72 v \mathrm{CCl}_{(1}$ & $\begin{array}{l}733.8\left({ }^{35} \mathrm{Cl}\right) \\
731.5\left({ }^{37} \mathrm{Cl}\right)\end{array}$ & 723 & 25.4 & $59 v \mathrm{CCl}_{(1)}+11 \delta \mathrm{CCCl}_{(1)}++10 v \mathrm{CCl}_{(2)}$ \\
\hline $\begin{array}{l}676.0 \\
672.2\left({ }^{35} \mathrm{Cl}\right) \\
669.0\left({ }^{37} \mathrm{Cl}\right)\end{array}$ & 676 & 38.5 & $63 v \mathrm{CCl}_{(2)}+10 \gamma \mathrm{C}-\mathrm{Cl}_{(2)}$ & $\begin{array}{l}632.0\left({ }^{35} \mathrm{Cl}\right) \\
627.8\left({ }^{37} \mathrm{Cl}\right)\end{array}$ & 632 & 16.3 & $74 v \mathrm{CCl}_{(2)}$ & $\begin{array}{l}622.3\left({ }^{35} \mathrm{Cl}\right) \\
618.4\left({ }^{37} \mathrm{Cl}\right)\end{array}$ & 621 & 13.9 & $57 v \mathrm{CCl}_{(2)}+15 v \mathrm{CCl}_{(1)}+14 v \mathrm{CC} \mathrm{s}$ \\
\hline- & 400 & 0.7 & $47 \delta \mathrm{CCC}+34 \gamma \mathrm{C}-\mathrm{Cl}_{(2)}$ & 411.0 & 410 & 4.0 & $\begin{array}{l}22 \gamma \mathrm{C}-\mathrm{Cl}_{(2)}+18 \delta \mathrm{CCCl}_{(1)}+14 \delta \mathrm{CCCl}_{(2)}+14 v \mathrm{CCl}_{(1)}+13 \\
\delta \mathrm{CCC}+12 v \mathrm{CC} \mathrm{s}\end{array}$ & $\begin{array}{l}529.7 \\
528.0 \\
525.9\end{array}$ & 527 & 5.4 & $\begin{array}{l}22 \delta \mathrm{CCCl}_{(1)}+18 \delta \mathrm{CCC}+18 \gamma \mathrm{C}-\mathrm{Cl}_{(2)}+16 \\
v \mathrm{Cll}_{(1)}+12 v \mathrm{CCl}_{(2)}\end{array}$ \\
\hline- & 349 & 1.4 & $\begin{array}{l}25 \delta \mathrm{CCC}+24 \gamma \mathrm{C}-\mathrm{Cl}_{(2)}+19 v \mathrm{CCl}_{(2)}+12 \\
\delta \mathrm{CCCl}_{(1)}\end{array}$ & - & 376 & 4.3 & $39 \gamma \mathrm{C}-\mathrm{Cl}_{(2)}+30 \delta \mathrm{CCCl}_{(2)}+13 \delta \mathrm{CCCl}_{(1)}$ & - & 331 & 1.8 & $47 \delta \mathrm{CCCl}_{(2)}+36 \delta \mathrm{CCC}$ \\
\hline- & 282 & 0.3 & $\begin{array}{l}57 \delta \mathrm{CCCl}_{(2)}+14 \delta \mathrm{CCCl}_{(1)}+10 \\
v \mathrm{CCl}_{(1)}+9 v \mathrm{CC} \text { as }\end{array}$ & - & 307 & 0.2 & $41 \delta \mathrm{CCC}+17 \delta \mathrm{CCCl}_{(2)}+14 \gamma \mathrm{C}-\mathrm{Cl}_{(2)}+10 \tau \mathrm{C}-\mathrm{C}_{(3)}$ & - & 328 & 1.9 & $38 \gamma \mathrm{C}-\mathrm{Cl}_{(2)}+25 \delta \mathrm{CCCl}_{(2)}+18 \delta \mathrm{CCC}$ \\
\hline- & 253 & 0.3 & $90 \tau \mathrm{C}-\mathrm{C}_{(3)}$ & - & 247 & 0.02 & $87 \tau C-C_{(3)}$ & - & 254 & 0.1 & $93 \tau \mathrm{C}-\mathrm{C}_{(3)}$ \\
\hline- & 205 & 5.5 & $\begin{array}{l}51 \delta \mathrm{CCCl}_{(1)}+19 \delta \mathrm{CCCl}_{(2)}+15 \delta \mathrm{CCC}+ \\
11 \gamma \mathrm{C}-\mathrm{Cl}_{(2)}\end{array}$ & - & 187 & 0.9 & $49 \delta \mathrm{CCCl}_{(1)}+23 \delta \mathrm{CCCl}_{(2)}+22 \delta \mathrm{CCC}$ & - & 196 & 0.5 & $\begin{array}{l}53 \delta \mathrm{CCCl}_{(1)}+11 \delta \mathrm{CCC}+11 \delta \mathrm{CCCl}_{(2)}+11 \gamma \mathrm{C}- \\
\mathrm{Cl}_{(2)}\end{array}$ \\
\hline - & 113 & 4.1 & $92 \tau \mathrm{C}-\mathrm{C}_{(1)}$ & - & 110 & 1.0 & $92 \tau \mathrm{C}-\mathrm{C}_{(1)}$ & - & 104 & 1.0 & $83 \tau \mathrm{C}-\mathrm{C}_{(1)}$ \\
\hline
\end{tabular}

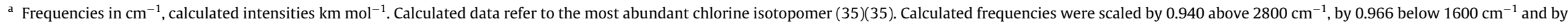
0.933 for $\mathrm{C}-\mathrm{Cl}$ stretching modes. The definitions of the internal coordinates are given in Supplementary Table S3 (Supplementary Material), only PED values $\geqslant$ than $10 \%$ are included. See Fig. 1 for atom numbering. 

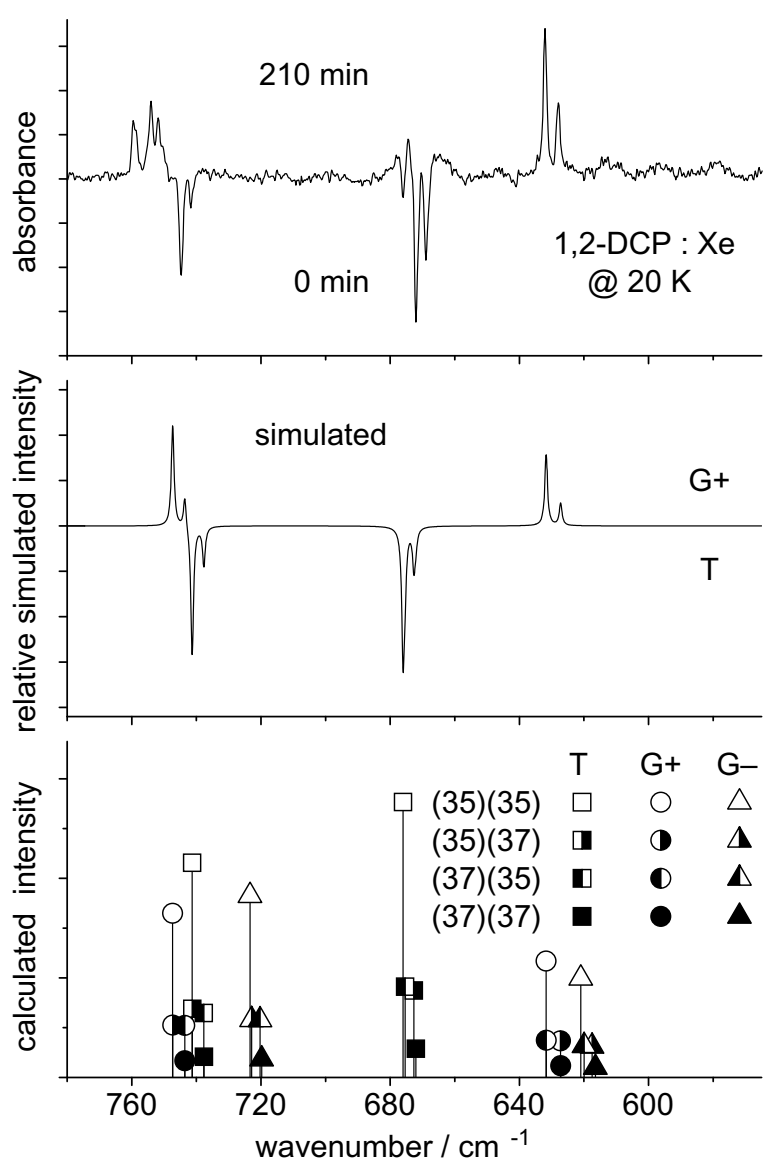

Fig. 4. Effect of broadband infrared irradiation on the spectrum of 1,2-DCP monomers isolated in a xenon matrix at $20 \mathrm{~K}(\nu \mathrm{CCl}$ region $)$. Top frame: Difference experimental FTIR spectrum, obtained as (spectrum of the sample after $210 \mathrm{~min}$ of irradiation) minus (spectrum of non-irradiated sample). Negative bands decrease and positive bands increase upon irradiation. Bottom frame: MP2/6-311++G(3df,3pd) calculated spectra of three conformers in four isotopic combinations of 1,2-DCP. Calculated wavenumbers were scaled by 0.933 . Calculated intensities were scaled by the natural isotopic abundance of chlorine atoms. Middle frame: Simulated difference spectrum where $\mathrm{T}$ conformer (negative bands) quantitatively transforms into $\mathrm{G}+$ (positive bands). In the simulation, Lorentzian functions were centered at the calculated (scaled) frequencies with bandwidth-at-half-height equal to $1 \mathrm{~cm}^{-1}$. Spectrum of conformer T was subtracted from that of conformer $\mathrm{G}^{+}$, while conformer $\mathrm{G}$ - was zeroed in the simulation.

sample prior to irradiation. The infrared-induced spectral changes are presented as a difference spectrum in top frame of Fig. 4. This Figure shows also clearly that while the bands of $\mathrm{T}$ conformer decreased in intensity, the bands belonging to $\mathrm{G}+$ rotamer increased. The assignment of the growing bands to $\mathrm{G}+$ turned to be possible after comparison with the theoretically predicted spectra, especially in the region of $v \mathrm{CCl}_{(1)}$ and $v \mathrm{CCl}_{(2)}$ vibrations, where the bands belonging to the three conformers are well separated (see Fig. 4).

Particularly interesting is the fact that the absorptions due to $\mathrm{G}$ - form did not increase upon irradiation. For example, the $v \mathrm{CCl}_{(1)}$ mode of conformer $\mathrm{G}$ - was theoretically predicted at ca. $720 \mathrm{~cm}^{-1}$, between two strong $v \mathrm{CCl}$ absorptions of conformer T. No band ascribable to the $v \mathrm{CCl}_{(1)}(\mathrm{G}-)$ vibration increased upon irradiation of the matrix (see Fig. 4). Indeed, comparison with the calculations showed that all bands growing in the experiment have relative positions, with respect to those of conformer $\mathrm{T}$, that can only be ascribable to conformer $\mathrm{G}+$. Based on this observation, a theoretical spectrum simulating irradiation-induced changes was constructed. In this simulation conformer $\mathrm{G}$ - was not included, while conformer $\mathrm{T}$ (all isotopic modifications) was assumed to convert into conformer G+ only. The result of this simulation is presented in the middle frame of Fig. 4. The simulated spectrum reproduces very well the experimentally observed changes, including band splitting caused by isotopic effects.

In order to verify this model (form $\mathrm{T}$ converts to $\mathrm{G}+$ and form $\mathrm{G}$ - remains intact), the simulated changes were compared to the experimental spectrum in the entire fingerprint region. This comparison is presented in Fig. 5 and exhibits a good general agreement. Special attention was paid to the spectral regions where absorptions due to $\mathrm{G}$ - form were predicted, but no bands increased in these regions, thus supporting the presented interpretation.

A possible explanation of non-conversion of conformer $\mathrm{T}$ into $\mathrm{G}$ - could be related with the potential energy profile for the internal rotation around the $\mathrm{Cl}-\mathrm{C}-\mathrm{C}-\mathrm{Cl}$ dihedral angle. The height of the torsional barrier in the $\mathrm{T} \rightarrow \mathrm{G}+$ direction is by $6.5 \mathrm{~kJ} \mathrm{~mol}^{-1}$ lower than in the $\mathrm{T} \rightarrow \mathrm{G}$ - direction (see Fig. 2). This difference shall increase in the low temperature matrix even more. The total dipole moment of the 'reactive' transition state $\mathrm{TS}_{\mathrm{TG}+}$ is ca. 2.2D vs. 1.7D for the 'non-reactive' transition state $\mathrm{TS}_{\mathrm{TG}-}$ (these transition states are indicated by arrows in the upper frame of Fig. 2). It should be noted that the most stable structure of 1,2-DCP, namely conformer $\mathrm{T}$, possesses the lowest molecular dipole moment $(0.56 \mathrm{D}$, see Fig. 2) among all stationary points. The difference in dipole moments implies that, in such polarizable medium as solid xenon, $\mathrm{TS}_{\mathrm{TG}}+$ undergoes a stronger stabilization with respect to $\mathrm{T}$ than $\mathrm{TS}_{\mathrm{TG}-\text {. }}$

It must be noticed that though the effective torsional barriers decrease in the xenon matrix comparing to the theoretically predicted values, they do not decrease to such extent to allow the thermal relaxation of the minor conformers $(\mathrm{G}+$ and $\mathrm{G}-$ ) into the most stable form $\mathrm{T}$. In a separate experiment, matrix samples were subjected to annealing, in an attempt to induce thermal changes in the relative population of the conformers. But even increasing the sample temperature up to $60 \mathrm{~K}$ (i.e.; the point where an extensive association of the compound starts) did not lead to any spectral change that can be related with conformational isomerization.

One of the interesting points of the IR-induced photochemical isomerization experiments now described is that the system under study does not possess either a hydroxyl or an amine substituent. Indeed, most of the IR-induced conformational isomerizations of matrix isolated molecules reported hitherto deal with molecules bearing hydroxyl or amine groups, whose stretching vibrations (either the fundamental modes or the first overtones) are excited in the initial reaction step [25-31]. Following this initial step, vibrational relaxation from the excited coordinate into the low frequency reactive coordinate takes place through a series of processes in cascade involving different vibrational states of the reactant species, which might be assisted by the lattice to compensate the energy mismatch between the intramolecular energy levels involved in the energy relaxation, converting the excess internal energy of the guest molecule into lattice phonons $[25,32,33]$. It has been suggested that in order to be efficient, this relaxation mechanism requires a low density of states of low energy, to prevent competition between the reactive channel and non-reactive energy dissipation channels [25,27]. For molecules having a high density of low energy vibrational states, as 1,2DCP (moreover without having a high energy vibrational mode like the $\mathrm{OH}$ stretching vibration that can act as primary energy acceptor), occurrence of IR-induced rotamerization can be taken as an indication of existence of a strongly preferred relaxation channel which couples the excited vibration (in this case presumably a $\mathrm{C}-\mathrm{H}$ stretching mode) to the reactive torsional coordinate [33]. The identification of this relaxation channel is not a trivial problem and is far beyond the capabilities of our experimental facilities. 


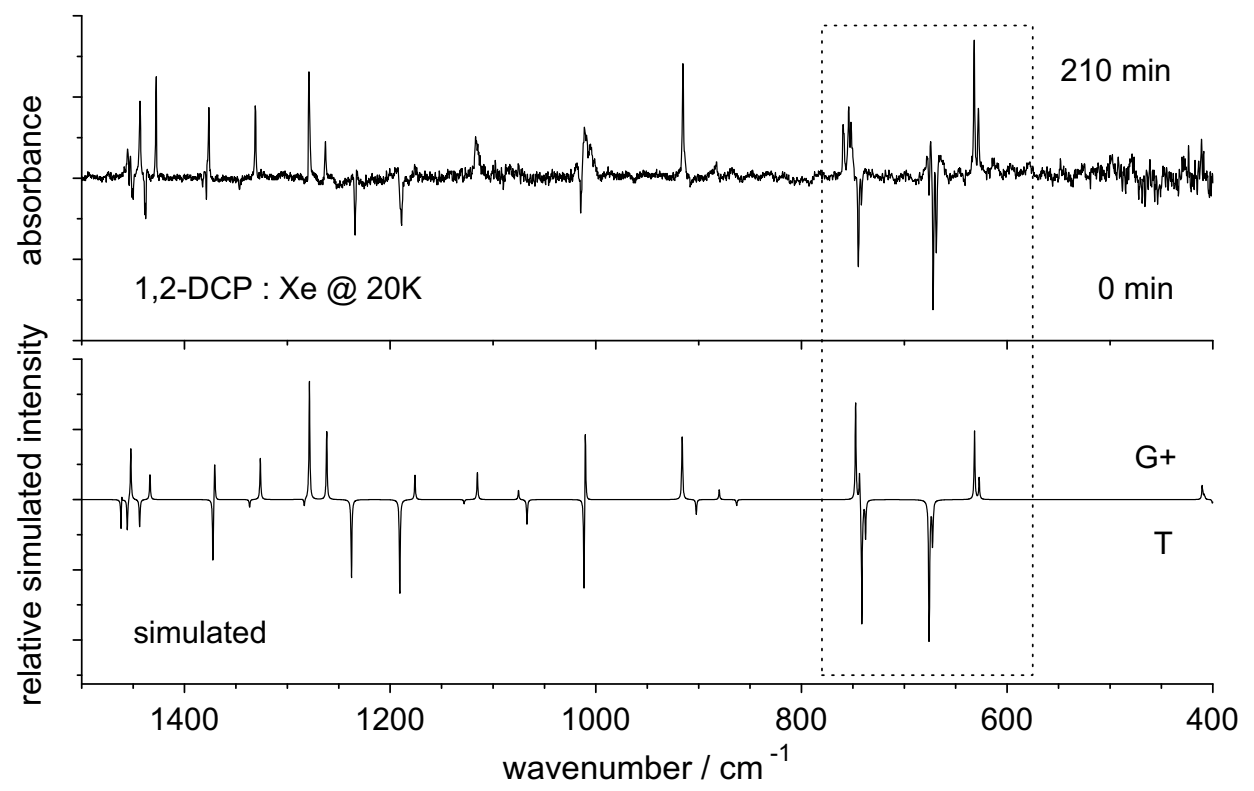

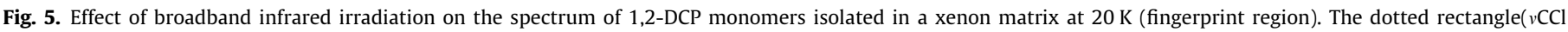

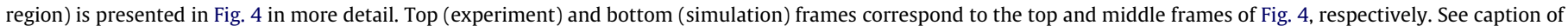
Fig. 4 for explanation.

\section{Conclusion}

Extensive conformational analysis has been performed for 1,2dichloropropane. The theoretical calculations predicted that the trans conformer, characterized by the $\mathrm{Cl}-\mathrm{C}-\mathrm{C}-\mathrm{Cl}$ dihedral angle of $173.6^{\circ}$, should be the lowest energy form and account for ca. $84 \%$ of the conformational population at $298 \mathrm{~K}$. In agreement with this result, conformer $\mathrm{T}$ was found to be the dominating form trapped in low temperature Xe matrix. Two higher energy gauche conformers ( $\mathrm{G}+$ and $\mathrm{G}-$ ) were also predicted by the calculations to have populations of ca. $8 \%$ at $298 \mathrm{~K}$, and could also be experimentally identified in the as-deposited xenon matrix of the compound. The spectrum of the matrix isolated compound is well reproduced by the superposition of the theoretically calculated spectra for individual conformers weighted by their predicted populations for the gas phase. This result indicates that the conformational mixture initially present in the gas phase was efficiently trapped in the matrix.

Broad band IR irradiation of the matrix isolated 1,2-DCP led to quantitative conversion of conformer $\mathrm{T}$ into $\mathrm{G}+$, while the population of conformer $\mathrm{G}$ - remained constant. Observation of IR-induced rotamerization in the studied molecule, which has a high density of low energy vibrational states, can be taken as an indication of existence of a strongly preferred intramolecular vibrational energy relaxation channel which couples the excited vibration (in this case presumably a $\mathrm{CH}$ stretching mode) to the reactive torsional coordinate. In addition, the observation of only the $\mathrm{T} \rightarrow \mathrm{G}^{+}$ isomerization could be correlated with the lower energy barrier associated with this process when compared with the $T \rightarrow G$ conversion.

Annealing of the matrix to temperature of ca. $60 \mathrm{~K}$ was found not to induce any isomerization process, which is consistent with the relatively high predicted energy barriers for conformational interconversion in 1,2-DCP.

Comparison of the calculated IR spectra for the three conformers with the experimental spectra, together with the results of the irradiation experiment, allowed for a detailed assignment of the experimental bands due to individual conformers of 1,2-DCP.

\section{Acknowledgments}

This work has been held under the POCI/QUI/58937/2004 research project, also supported by FEDER. The calculations have been carried out in Wroclaw Centre for Network and Supercomputing, Poland. A.O.-M. is grateful to the Portuguese Chemical Society, the University of Coimbra and Dr. Marilyn Jacox for the financial support associated with the George C. Pimentel Prize in Matrix Isolation 2005, which covered her stay at the Laboratory for Molecular Cryospectroscopy and Biospectroscopy of the University of Coimbra (Department of Chemistry).

\section{Appendix A. Supplementary data}

Supplementary data associated with this article can be found, in the online version, at doi:10.1016/j.cplett.2008.03.032.

\section{References}

[1] F.E. Löffler, J.E. Champine, K.M. Ritalahti, S.J. Sprague, J.M. Tiedje, Appl. Environm. Microbiol. 63 (2007) 2870.

[2] Agency for Toxic Substances and Disease Registry (ATSDR), 1989, Public statement: 1,2-dichloropropane. <http://www.atsdr.cdc.gov/toxprofiles/tp134-c5. pdf $/>$.

[3] H. van Dijk, Pestc. Sci. 11 (1980) 625.

[4] A.B. Dempster, K. Price, N. Sheppard, Spectrochim. Acta A 25 (1969) 1381.

[5] A.B. Dempster, K. Price, N. Sheppard, Spectrochim. Acta A 27 (1971) 1563.

[6] B.N. Cyvin, S.J. Cyvin, Acta Chem. Scand. 26 (1972) 3943.

[7] J. Thorbjørnsrud, O. Ellestad, P. Klaboe, T. Torgrimsen, J. Mol. Struct. 15 (1973) 45.

[8] T.A. Mohamed, H.D. Stidham, G.A. Guirgis, M.S. Afifi, J.R. Durig, J. Mol. Struct. 299 (1993) 111.

[9] G.A. Guirgis, Y.D. Hsu, A.C. Vlaservich, H.D. Stidham, J.R. Durig, J. Mol. Struct. 378 (1996) 83

[10] S. Mizushima, T. Shimanouchi, K. Nakamura, M. Hayashi, S. Tsuchiya, J. Chem. Phys. 26 (1957) 970.

[11] T.J. Tague Jr., P.M. Kligmann, C.P. Collier, M.A. Ovchinnikov, C.A. Wight, J. Phys. Chem. 96 (1992) 1288.

[12] H. Nomura, S. Koda, K. Hamada, J. Chem. Soc. Faraday Trans. I 84 (1988) 1267.

[13] Y. Haas, U. Samuni, Progr. React. Kinet. 23 (1998) 211.

[14] I. Reva, A. Simão, R. Fausto, Chem. Phys. Lett. 406 (2005) 126

[15] A. Borba, A. Gómez-Zavaglia, R. Fausto, J. Mol. Struct. 794 (2006) 196.

[16] S. Breda, I.D. Reva, R. Fausto, J. Phys. Chem. A 110 (2006) 11034. 
[17] I.D. Reva, S. Jarmelo, L. Lapinski, R. Fausto, J. Phys. Chem. 108 (2004) 6982.

[18] M.J. Frisch et al., Gaussian 03, Revision C.02, Gaussian, Inc., Wallingford CT, 2004.

[19] C. González, H.B. Schlegel, J. Phys. Chem. 90 (1989) 2154.

[20] C. González, H.B. Schlegel, J. Phys. Chem. 94 (1990) 5523.

[21] E. Hirota, Y. Endo, S. Saito, J.L. Duncan, J. Mol. Spectrosc. 89 (1981) 285

[22] W. Stahl, H. Dreizler, M. Hayashi, Z. Naturforsch. A 38 (1983) 1010.

[23] A. de Luis, J.C. López, J.L. Alonso, Chem. Phys. 248 (1999) 247.

[24] A. Chung-Phillips, J. Mol. Struct. (THEOCHEM) 89 (1992) 417.

[25] E.M.S. Maçôas, L. Khriachtchev, M. Pettersson, J. Juselius, R. Fausto, M. Räsänen, J. Chem. Phys. 119 (2003) 11765.
[26] J.D. Baldeschwieler, G.C. Pimentel, J. Chem. Phys. 33 (1960) 1008.

[27] E.M.S. Maçôas, L. Khriachtchev, M. Pettersson, R. Fausto, M. Räsänen, J. Am. Chem. Soc. 125 (2003) 16188

[28] E.M.S. Maçôas, L. Khriachtchev, M. Pettersson, J. Lundell, R. Fausto, M. Räsänen, Vib. Spectrosc. 34 (2004) 73, and references cited therein.

[29] M. Nakata, M. Tasumi, Spectrochim. Acta A 41 (1985) 341

[30] H. Takeuchi, M. Tasumi, Chem. Phys. 77 (1983) 21.

[31] H. Takeuchi, M. Tasumi, Chem. Phys. 70 (1982) 591.

[32] V.E. Bondybey, Annu. Rev. Phys. Chem. 35 (1984) 591

[33] P. Roubin et al., J. Chem. Phys. 107 (1997) 7800. 